\title{
Research Article \\ Evaluation of Heat Removal from RBMK-1500 Core Using Control Rods Cooling Circuit
}

\author{
A. Kaliatka, E. Uspuras, and M. Vaisnoras \\ Lithuanian Energy Institute, 3 Breslaujos street, 44403 Kaunas, Lithuania \\ Correspondence should be addressed to A. Kaliatka, algis@mail.lei.lt
}

Received 8 October 2007; Accepted 4 April 2008

Recommended by Oleg Melikhov

The Ignalina nuclear power plant is a twin unit with two RBMK-1500, graphite moderated, boiling water, multichannel reactors. After the decision was made to decommission the Ignalina NPP, Unit 1 was shut down on December 31, 2004, and Unit 2 is to be operated until the end of 2009. Despite of this fact, severe accident management guidelines for RBMK-1500 reactor at Ignalina NPP are prepared. In case of beyond design basis accidents, it can occur that no water sources are available at the moment for heat removal from fuel channels. Specificity of RBMK reactor is such that the channels with control rods are cooled with water supplied by the system totally independent from the reactor cooling system. Therefore, the heat removal from RBMK-1500 reactor core using circuit for cooling of rods in control and protection system can be used as nonregular mean for reactor cooldown in case of BDBA. The heat from fuel channels, where heat is generated, through graphite bricks is transferred in radial direction to cooled CPS channels. This article presents the analysis of possibility to remove heat from reactor core in case of large LOCA by employing CPS channels cooling circuit. The analysis was performed for Ignalina NPP with RBMK-1500 reactor using RELAP53D and RELAP5 codes. Results of the analysis have shown that, in spite of high thermal inertia of graphite, this heat removal from CPS channels allows to slow down effectively the core heat-up process.

Copyright (C) 2008 A. Kaliatka et al. This is an open access article distributed under the Creative Commons Attribution License, which permits unrestricted use, distribution, and reproduction in any medium, provided the original work is properly cited.

\section{INTRODUCTION}

RBMK-1500 reactor, which is located at the Ignalina NPP site, is multichannel boiling water and graphite moderated nuclear reactor. Reactor core consists of 2488 graphite columns with the vertical bore openings [1]. These openings are used for positioning of the fuel channels, which in turn are used for placing fuel assemblies, reactivity regulating control rods, and several types of instruments into the core. Approximately, 95\% of energy is generated in fuel assemblies, while $5 \%$ in graphite columns. Specificity of RBMK reactor is such that the control rods are placed in the individual channels that are independent from the channels with fuel bundles. The channels with control rods are cooled with water supplied by the system totally independent from the reactor cooling system. The pressure in channels with control rods is always close to atmospheric. The geometry of the graphite columns and availability of FC and the channels of control and protection system located near by results in nonuniformity of heat fluxes and temperature distributions around the graphite columns periphery. Thus, in order to model the thermal hydraulic behavior in the RBMK core, it is necessary to represent heat conduction between the graphite columns. On the other hand, the heat removal from reactor core using CPS cooling system can be used as nonregular mean for reactor cooldown in case of beyond design-basis accidents. In BDBA, it can occur that no water sources are available at the moment for heat removal from FC [2], but the removal of heat from reactor core by CPS cooling circuit is possible, since 211 CPS channels are distributed evenly in the reactor core (see Figure 1). These channels are filled with water supplied by the low-pressure system totally independent from the reactor cooling system (RCS). Thus, the large break in reactor cooling system does not disturb usage of the CPS cooling circuit. The proportion between channels with fuel assemblies and channels with control rods is $1661 / 211=7.87$. Thus, we can assume that one CPS channel is environed by 8 FCs. The heat from fuel channels, where heat is generated, through graphite bricks is transferred in radial direction to cooled CPS channels (see Figure 2). 

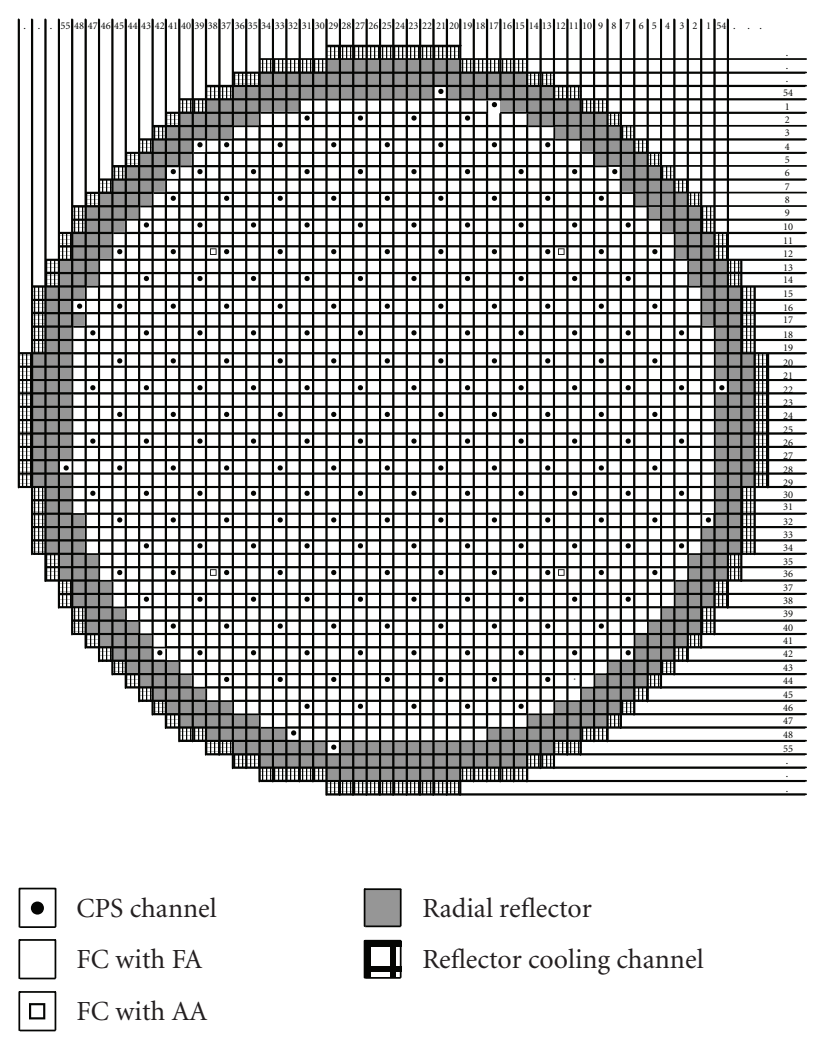

FIGURE 1: Distribution of fuel channels, CPS channels and graphite reflector cooling channels in the reactor core.

Thus, this article presents the analysis of heat removal by employing CPS channels cooling circuit. The analysis was performed for Ignalina NPP with RBMK-1500 reactor.

\section{ASSESSMENT OF HEAT TRANSFER TRANSFERRED IN RADIAL DIRECTION BETWEEN ADJACENT GRAPHITE COLUMNS}

\subsection{Simulation of heat transfer transferred in radial direction by employing the interstructure heat conduction model}

For the simulation of heat transfer between fuel channels and CPS channels the RELAP5-3D code [3] was used. RELAP53D code has the interstructure heat conduction model. This heat conduction enclosure model gives RELAP5-3D a general multidimensional heat conduction capability. As it was demonstrated by Paik [4], this model is applied to calculation of heat transfer through the gas gap between the RBMK reactor core graphite blocks.

The nodalization scheme of the developed model is presented in Figure 3. The one single CPS channel (3) with surrounding graphite column is modeled by "pipe" element with heat structure. The water in this channel is supplied from water tank of additional hold-down system (1) through pipeline (2) and bottom distribution header (4). The tank of AHS is elevated $30 \mathrm{~m}$ up to the bottom of reactor core. The steam from the CPS channel is removed in to top distribution header (5). The pressure in this header is atmospheric.

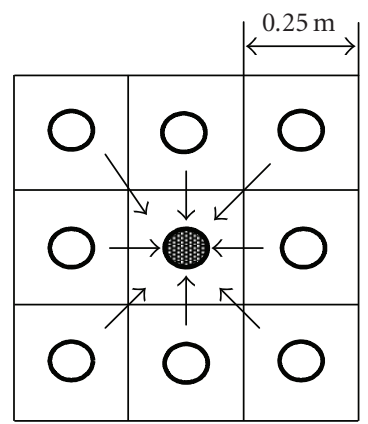

Figure 2: Heat transfer from FCs to cooled CPS channel.

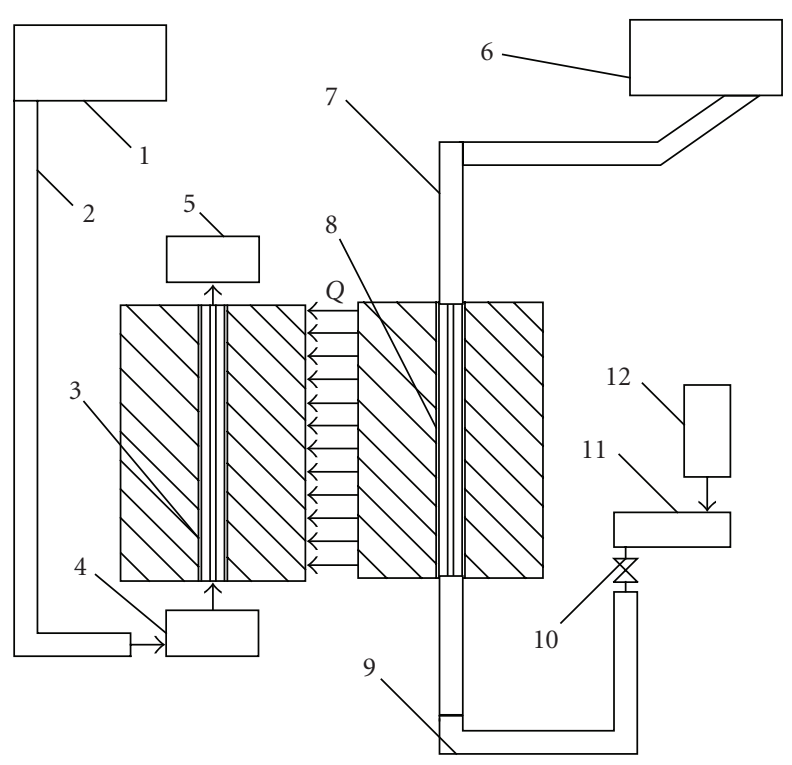

FIGURE 3: Simplified model of Ignalina NPP for thermal-hydraulic analysis of processes in RCS (for RELAP5-3D code): (1) water tank of AHS, (2) pipeline, (3) CPS channel, (4) bottom distribution header, (5) top distribution header, (6) model of DS and steam lines, (7) steam-water pipeline, (8) eight fuel channels, (9) bottom water pipeline, (10) individual control valve, (11) GDH, (12) water supply from MCP pressure header.

Eight FCs (8), placed in the graphite columns, are surrounding this single CPS channel. These channels are fed by water from volume (12), which models water supply from MCP pressure header. Water from GDH, which is modeled by "branch" element (11), is supplied into bottom water pipeline (9) and later into fuel channels (8). The water flow through FC is regulated using individual control valve (10). The steam water mixture is directed to the DS and steam-line model (6), through steam water pipeline (7). The volumes $(1,5,6$, and 12$)$ are modeled by "time-dependent" elements with specified boundary conditions.

\subsection{Gas gap conductance between adjacent graphite blocks}

The graphite columns in RBMK-type reactors are separated by a small $(\sim 1 \mathrm{~mm})$ gap. The gas gaps between graphite 
columns are filled with a gas mixture $(40 \%$ of $\mathrm{He}$ and $60 \%$ of $\mathrm{N}_{2}$ by volume fraction) [1]. For establishing of the gas gap conductance between adjacent graphite blocks, the additional calculation was performed. The problem consists of two graphite blocks separated by a gap (see Figure 4).

Heat transfer coefficient of the gas gap (gap conductance) can be expressed [5]:

$$
\alpha=\frac{\lambda_{e}}{\delta}
$$

where

$$
\lambda_{e}=\lambda_{\mathrm{gas}} \cdot \varepsilon_{k}
$$

In (2), $\lambda_{\text {gas }}$ is the thermal conductivity coefficient of gas, and $\varepsilon_{k}$ is the convection coefficient. Convection coefficient is equal to

$$
\varepsilon_{k}=c \cdot\left(\mathrm{Gr}_{\delta} \cdot \operatorname{Pr}_{\delta}\right)^{n}
$$

where coefficient $c$ and exponent $n$ depend from Grashof number $\left(\mathrm{Gr}_{\delta}\right)$ and Prandtl number $\left(\mathrm{Pr}_{\delta}\right)$ for the gap product. If $\mathrm{Gr}_{\delta} \cdot \operatorname{Pr}_{\delta}<1 \cdot 103$, then $c=1.0, n=0.0$. If $1 \cdot 103 \leq$ $\mathrm{Gr}_{\delta} \cdot \operatorname{Pr}_{\delta} \leq 1 \cdot 106$, then $c=0 \cdot 105, n=0 \cdot 3$. If $1 \cdot 106 \leq$ $\mathrm{Gr}_{\delta} \cdot \operatorname{Pr}_{\delta} \leq 1 \cdot 1010$, then $c=0.4, n=0.2$.

Since for He and $\mathrm{N}_{2}$ gas $\mathrm{Gr}_{\delta} \cdot \operatorname{Pr}_{\delta}<1 \cdot 103$, then $\varepsilon_{k}=1$ and $\lambda_{e}=\lambda_{\text {gas }}$.

According to RBMK designers [5], thermal conductivity coefficient can be expressed as follows:

$$
\lambda_{\mathrm{gas}}=\left(a+b \cdot T_{\mathrm{av}}\right) \cdot 10^{-3},
$$

where coefficients $a$ and $b$ depend on the He concentration (for the gas mixture $40 \%$ of $\mathrm{He}$ and $60 \%$ of $\mathrm{N}_{2}, a=58$ and $b=0.09), T_{\mathrm{av}}$-average gas temperature in the gap (it is assumed that the gas temperature is equal to the average temperature of the graphite surface $750 \mathrm{~K}$ ). Using (4), we obtain that $\lambda_{\text {gas }}=0.1255 \mathrm{~W} / \mathrm{m} \cdot \mathrm{K}$. Then, the heat transfer coefficient of the gas gap (according to (1)) $\alpha=$ $104.6 \mathrm{~W} / \mathrm{m}^{2} \cdot \mathrm{K}$.

\subsection{Validation of the gas gap conductance model}

The values of the determined heat transfer coefficient of the gas gap between adjacent graphite blocks were used in the "heat conductance" model [3] of the RELAP5-3D input, set for the simulation of the problem. Using the RELAP5$3 \mathrm{D}$ code, the steady-state condition of RBMK-1500 reactor, including the reactor cooling system operating conditions during the reactor operation on $4000 \mathrm{MW}$ thermal power, was simulated. As could be seen from Figure 5, the calculated values of the graphite blocks outer surface temperature for the maximum and minimum power fuel channels are in reasonable agreement with the measured plant data [6].

Such achieved correspondence of the measured data and the calculation results obtained using the RELAP5-3D code allows to conclude that the selected methodology for the modeling of the heat transfer in RBMK reactor core is suitable.

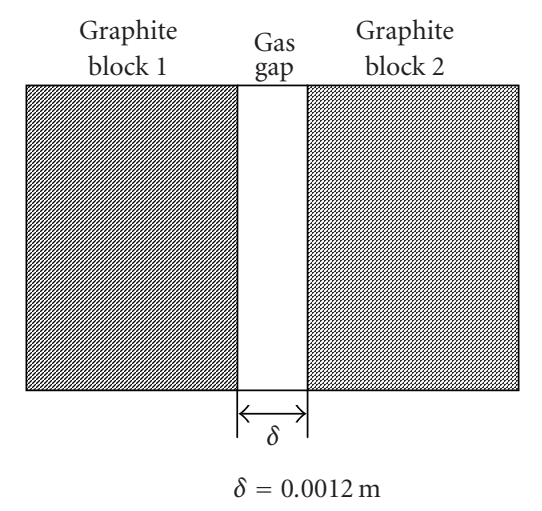

FIGURE 4: Schematic of two adjacent graphite blocks.

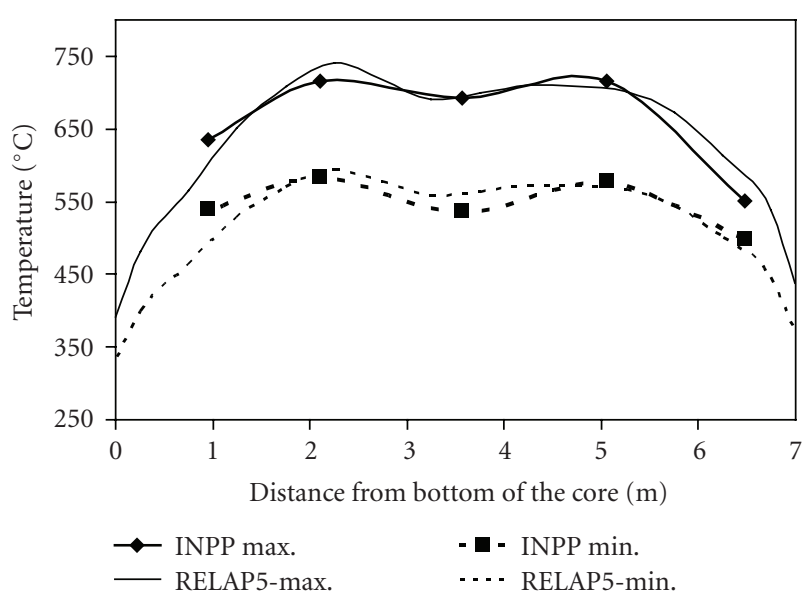

FIGURE 5: The calculated values of the graphite blocks outer surface temperature for the maximum and minimum power fuel channels (reactor power $4000 \mathrm{MW}$ ).

\section{EVALUATION OF AMOUNT OF HEAT, WHICH CAN BE REMOVED BY EMPLOYING COOLING OF CPS CHANNELS}

The evaluation of amount of heat, which can be removed by employing cooling of CPS channels, was performed for two boundary cases:

(i) the possibility to remove the heat from graphite in case of station blackout, when all pumps are tripped;

(ii) the possibility to remove the heat from graphite in case of large break LOCA, when CPS channels cooling system remains in operation.

\subsection{Evaluation of amount of removed heat from graphite stack by CPS channels in station blackout case}

In the station blackout case due to of loss electrical power supply MCPs, the pumps of the service water system and feedwater supply pumps are switched off. Station blackout case assumes the failure on start-up of all diesel generators, which leads to the unavailability of the ECCS pumps. The 
reactor scram signal is activated due to signal of MCP trip. The pressure in RCS remains nominal after the accident. The water is evaporating in the fuel channels due to decay heat; the generated steam is removed through main safety valves that keep the nominal pressure in RCS (see Figure 6).

The analysis of processes in reactor core and RCS in case of station blackout (when heat removal using CPS channels is not taken into account) is presented in articles [7, 8]. It was shown that within first 0.5 hour after beginning of accident the reactor is cooled by natural circulation. Later, after water resource in DSs is evaporated and discharged through MSV, the heat-up of core components begins. It appears only $\sim 1.5$ hours after the beginning of the accident (see Figure 7 ). In case of station blackout, $\sim 3$ hours after the beginning of the accident, the failure of fuel channels is expected because the pressure in RCS is nominal, and the acceptance criterion for $\mathrm{FC}$ wall $650^{\circ} \mathrm{C}$ [9] will be reached (Figure 7). In the present analysis, the opening of one safety relief valve at time moment $\sim 3.8$ hours after the accident beginning by an operator to discharge steam was assumed. Due to pressure decrease after valve opening the rest of coolant in pipelines below reactor core starts to boil and steam cools down the core for a short time span. However, at time moment 4.3 hours the second (repeated) heat-up of core elements starts. After operator starts depressurization, the accident scenario would continue at low pressure (Figure 7).

The analysis of possibility to remove heat from reactor core in case of station blackout by employing cooling of CPS channels was performed using RELAP5-3D model, shown in Figure 3. In case of station blackout, the water supply in the CPS rods cooling channels is interrupted due to loss of power to pumps. The control rods will be cooled the first 10 minutes by water flow from the top distribution tank of CPS because of water resource in this tank. After emptying this tank, the temperature of CPS channels walls is increasing (see Figure 7). However, there is a possibility to fill the tank of AHS (see Position 1 in Figure 3) by artesian water. The tank of AHS, which is elevated $30 \mathrm{~m}$ up to the bottom of reactor core, can be connected to the bottom distribution header of CPS (see Position 4 in Figure 3 ) for water supply to control rod channels (see Position 3 in Figure 3). It was assumed during the modeling that the tank of AHS is connected to CPS channels 1 hour after the beginning of the accident. It takes 10 additional minutes for water to enter the bottom part of CPS channels. The supplied water starts to boil and vapor will escape through pipelines, connected to the top part of channels (see Position 5 in Figure 3). At the time moment, when the water supply in to CPS channels starts, the control rods and their channels walls are already hot. As it is presented in Figures 7-10, the CPS channel wall temperature reaches approximately $400^{\circ} \mathrm{C}$. It is because these channels have received heat from hot graphite stack. The temperature of FCs walls is lower $\left(\sim 300^{\circ} \mathrm{C}\right)$ because the rest of water from RCS cools fuel channels at this moment. After the start of water supply, the bottom part of CPS channels will be cooled. Temperature of CPS channel wall is approximately $100^{\circ} \mathrm{C}$ that means boiling of water in channels. The water in CPS channels removes the heat from graphite bricks, thus temperature

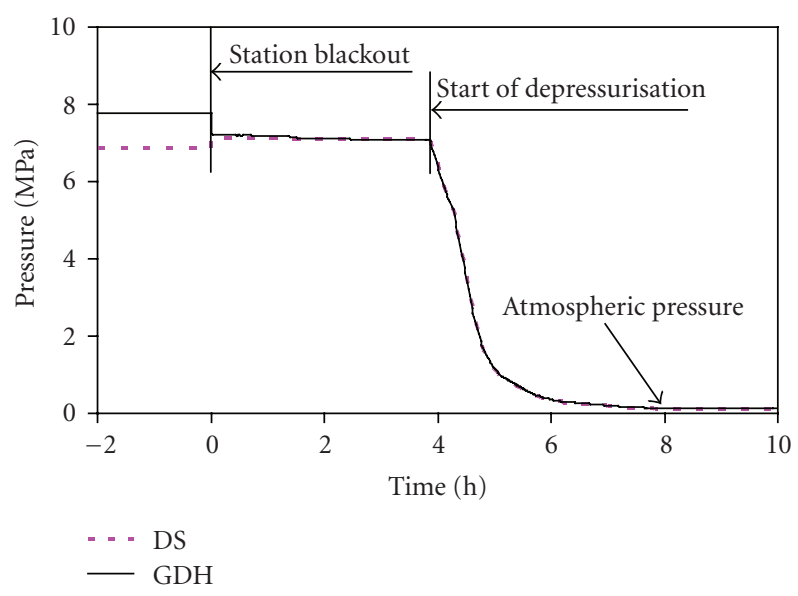

Figure 6: Station blackout case. Pressure behaviour in RCS.

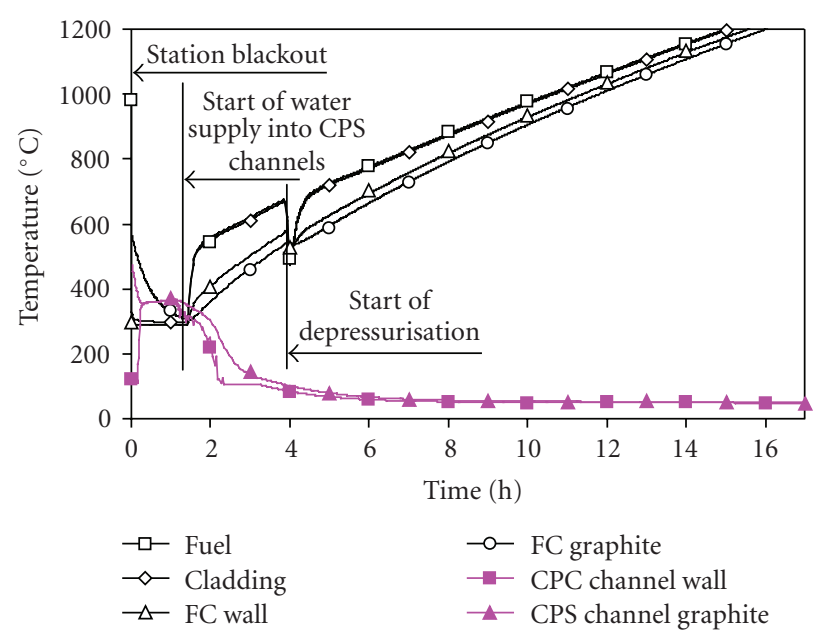

FIgURE 7: Station blackout case. Heat removal using CPS channels is not taken into account. Behaviour of core components temperatures.

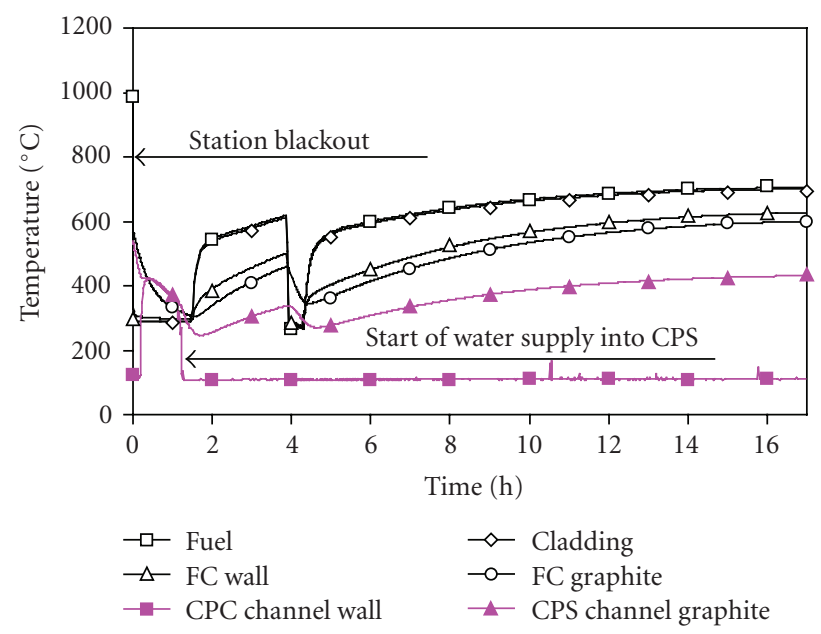

FIGURE 8: Station blackout case. Heat removal using CPS channels is taken into account. Behaviour of core components temperatures at the elevation $1.75 \mathrm{~m}$ from core bottom. 


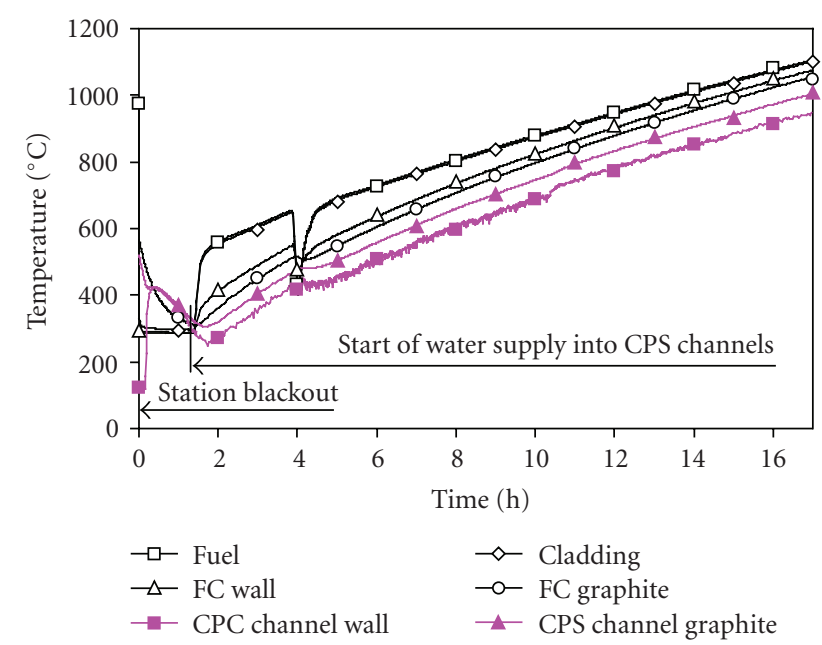

Figure 9: Station blackout case. Heat removal using CPS channels is taken into account. Behaviour of core components temperatures at the elevation $5.25 \mathrm{~m}$ from core bottom.

of graphite of CPS channel is below the temperature of graphite of fuel channels (Figures 8 and 9). The part of heat from FCs is transferred in radial direction through graphite columns and gaps between graphite columns into cooled CPS channels. However, the flow rate of water from AHS tank is not sufficient for effective cooling of CPS channels. As it is presented in Figures 9 and 10, the temperature of CPS channels walls in the top part is much higher. 17 hours after the beginning of the accident peak, CPS channel wall temperature reaches $1000^{\circ} \mathrm{C}$. To prevent generation of huge amount of hydrogen, the operator should stop the water supply into CPS channels at this moment. As it is shown in Figure 10, the maximum capacity of heat removal in such way is equal to $15 \mathrm{MW}$ (the water is supplied into $211 \mathrm{CPS}$ channels). The decay heat, generated in the reactor, decreases down to such power level only approximately 100 hours after the beginning of the accident (see Figure 11). Thus, the water supply from AHS tank into CPS channels in case of station blackout is not effective enough and cannot remove all heat from reactor core, but such restoration of water supply into CPS channels allows to slow down the core heat-up process and may be used in complex with other measures.

\subsection{Evaluation of amount of removed heat from graphite stack by CPS channels in large break LOCA case}

For illustration of possibility to remove heat from reactor core using CPS cooling system, the case of break of RCS pipeline with the largest diameter (guillotine break of MCP pressure header) with failure of ECCS is presented in this article. In this BDBA case, only two means for reactor cooldown are assumed: injection of $\sim 180 \mathrm{~m}^{3}$ of water from ECCS hydroaccumulators and availability of CPS channels cooling circuit with capacity of heat removal $28.5 \mathrm{MW}$. The structure of coolant flows in case of this event is presented in Figure 12. It is assumed in the modeling that before the

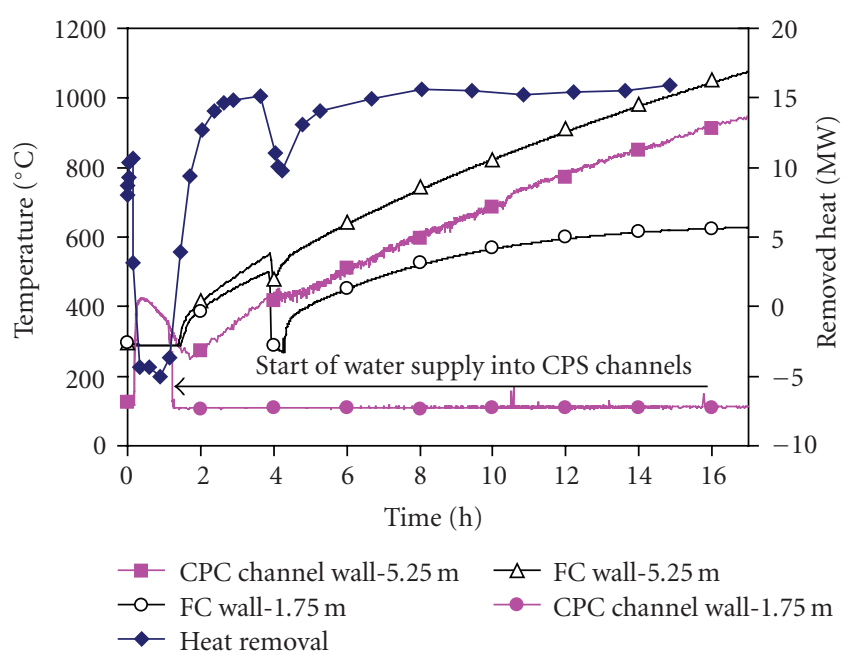

FIGURE 10: Station blackout case. Heat removal using CPS channels is taken into account. Behaviour of core components temperatures. Capacity of heat removal from the core by CPS cooling circuit.

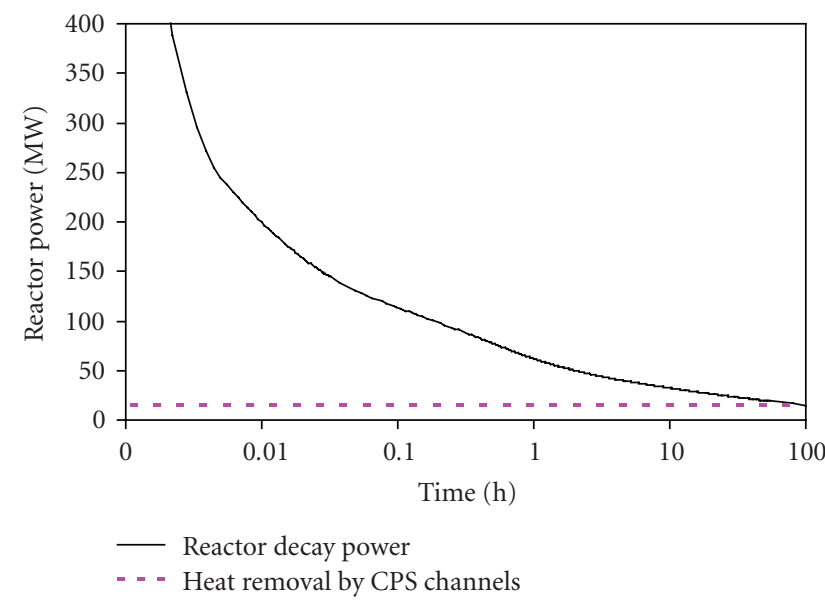

FIGURE 11: Comparison of reactor decay heat with capacity of heat removal from core by CPS cooling circuit in station blackout case.

accident the reactor operates at maximum allowed power level $4200 \mathrm{MW}$.

The behavior of pressure in the GDH and DS, coolant flow rate through channels in the affected RCS loop, is presented in Figures 13 and 14. It was assumed during the modeling that supply of water into CPS channels is keeping constant the temperature in the CPS channels. It was assumed that these channels are always filled with boiling water.

The behavior of maximum temperatures of fuel, cladding, FC wall, graphite columns, and CPS channel wall in case of MCP pressure header break with failure of ECCS within first 220 minutes is presented in Figure 15. As it is shown in this figure, after temperature in graphite columns with FC starts increasing, the temperature of graphite column with CPS starts to increase too but with some delay. This indicates that heat from overheated fuel channels is 


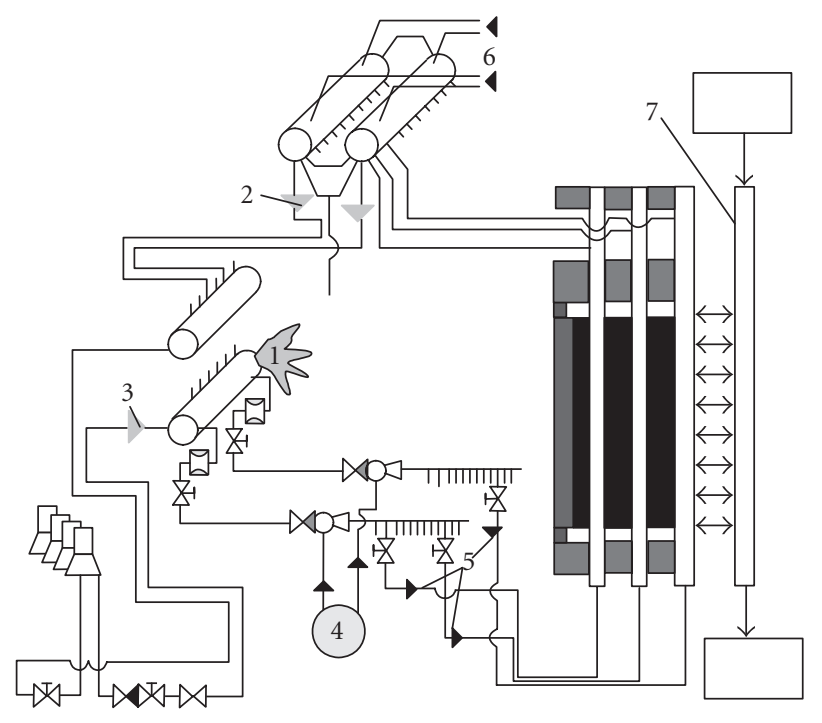

FIGURE 12: MCP pressure header break with failure of ECCS (except ECCS hydro accumulators): (1) pressure header break; (2) discharge of coolant from drum separators in the affected loop; (3) discharge of coolant from lower part of reactor cooling circuit in the affected loop; $(4,5)$ supply of water from ECCS hydroaccumulators; (6) supply of steam from DSs in in the intact loop; (7) circuit for cooling of rods in reactor control and protection system.

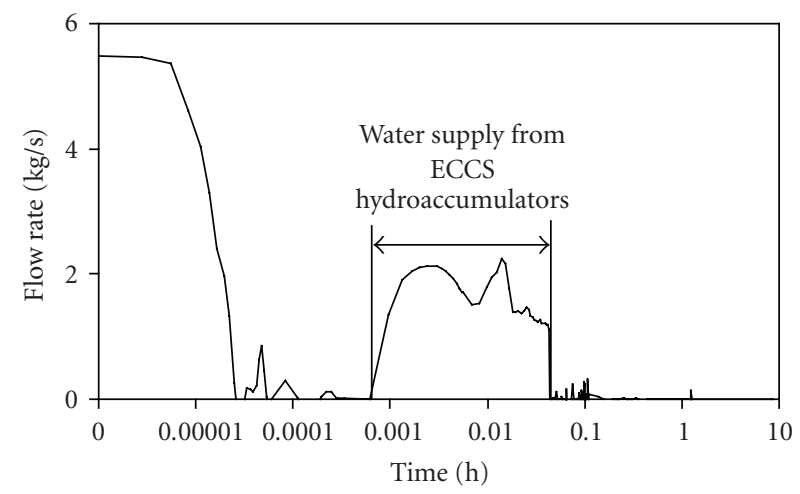

FIgURE 13: MCP pressure header break with failure of ECCS. Coolant flow rate through the single FC.

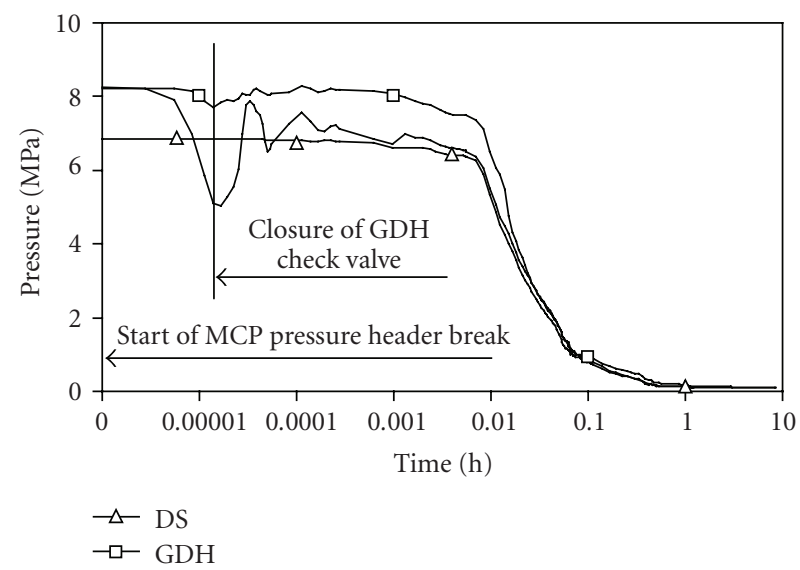

FIgURE 14: MCP pressure header break with failure of ECCS. Pressure behaviour in DS and GDH.

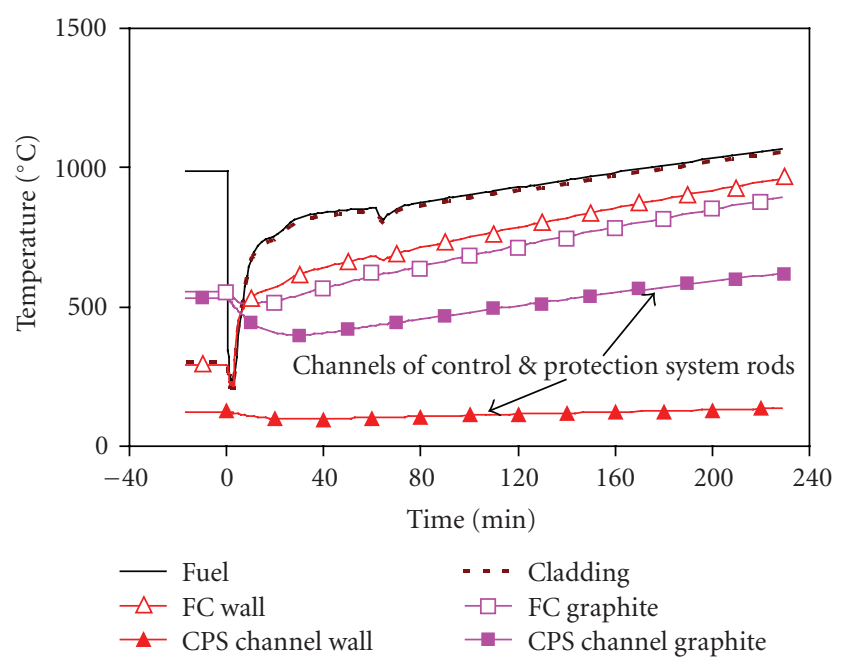

FIGURE 15: MCP pressure header break with failure of ECCS. The heat transfer from FC channels to CPS cooling channels is taken into account. Behaviour of maximum temperatures of fuel, cladding, FC wall, graphite columns and CPS channel wall.

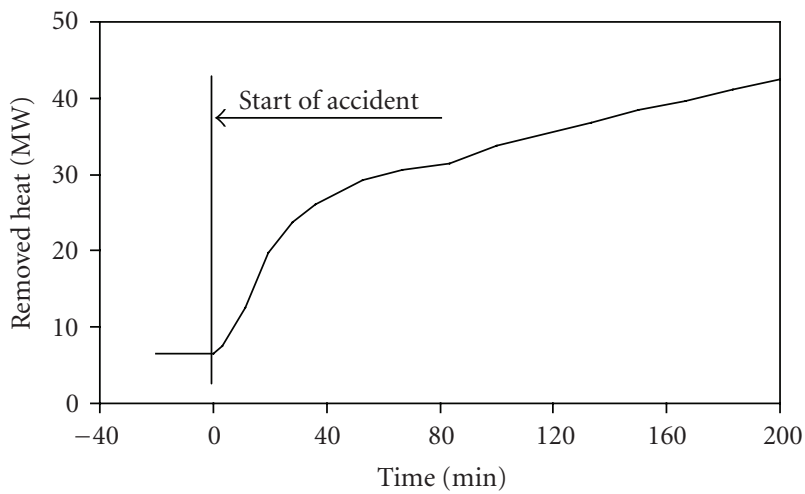

FIGURE 16: MCP pressure header break with failure of ECCS. Heat removal from fuel channels through $211 \mathrm{CPS}$ channels by CPS cooling system.

transferred in radial direction through the graphite bricks and gas gaps between these graphite bricks into cooled CPS channels, as shown schematically in Figure 2. The temperature of graphite with CPS channels is always lower than temperature of graphite with FC. The code RELAP5-3D is not designed to model severe accident, thus the calculation is terminated after fuel channel wall temperature reaches $950^{\circ} \mathrm{C}$.

The amount of heat that is transferred from fuel channels to CPS channels was calculated using the presented RELAP53D model. The total amount of heat removed by 211 CPS channels is presented in Figure 16. As it is seen from this figure, during normal operation, approximately $7-8 \mathrm{MW}$ of heat is removed from reactor core by CPS channel cooling system. In case of accident, when graphite temperature increases, the amount of removed heat also increases up to $40 \mathrm{MW}$. The amount of removed heat is proportional to the temperature difference between graphite column 
with overheated FC and graphite column with cooled CPS channels. As it is seen from Figure 15, during normal operation of reactor, the temperatures of graphite columns with fuel channels and with CPS channels are similaronly insignificant amount of heat is removed from reactor core by system of CPS channels cooling. In case of accident, after dryout and overheating of fuel channels (the cooling of CPS channels remains available), the temperature difference between CPS and FC graphite columns starts to increase (see Figure 15). This leads to increasing of amount of removed heat from hot FCs (see Figure 16).

Based on the simulation performed using RELAP5-3D code, the dependency of capacity of removed heat from temperature of FCs graphite column was established. As it is presented in Figure 17, if graphite temperature is increasing, the capacity of removed heat is increasing as well. At graphite temperature $700^{\circ} \mathrm{C}$, the maximal constant value of heat removal from fuel channels $(28.5 \mathrm{MW})$ is reached. The modeling of processes in reactor fuel channels in case of mentioned BDBA, when part of decay heat is removed by employing cooling of CPS channels, was performed using RELAP/SCDAPSIM model, described in [8]. The behavior of temperature of core components is presented in Figure 18. Due to loss of coolant in reactor cooling system, the heat-up of core components starts a few minutes after the beginning of the accident (Figure 18). The graphite stack, which is a moderator in RBMK-1500 reactor, is an efficient heat sink and slows down the heat-up of the core. As it is presented in Figure 18, due to the removal of heat from CPS channels, the peak fuel temperatures are below $1000^{\circ} \mathrm{C}$. Assuming heat removal, using CPS channels cooling circuit, approximately 16 hours after the beginning of the accident, a slow decrease of core components temperature begins. This is because decay heat, generated in the core, at this time moment decreases down to the level of heat, which is removed from CPS channels-28.5 MW, when CPS channels cooling circuit is available (Figure 19).

The cool-down process is very slow because after the decrease of graphite temperature the temperature gradient from fuel channels to control rods channels is decreasing as well. Thus, the amount of removed heat is decreasing. To evaluate the influence of the heat removal effect from the reactor core using a CPS cooling system, the simulated temperatures are compared with the case where the heat transfer to CPS channels is not taken into account. As it is presented in Figure 18, in the last case the temperatures of core components are increasing continuously because all decay heat, generated in the reactor core, is used for heating of core components. In this case after $\sim 10$ hours, the $1450^{\circ} \mathrm{C}$ temperature is reached and the melting of stainless steel grids in fuel assemblies starts. Later, $\sim 40$ hours after the beginning of the accident the temperatures increase up to $2400-2600^{\circ} \mathrm{C}$ and ceramic formation in fuel assemblies starts.

\section{CONCLUSIONS}

The analysis of possibility to remove heat from RBMK-1500 reactor core in case of large LOCA by employing cooling of CPS channels was performed using RELAP5-3D and

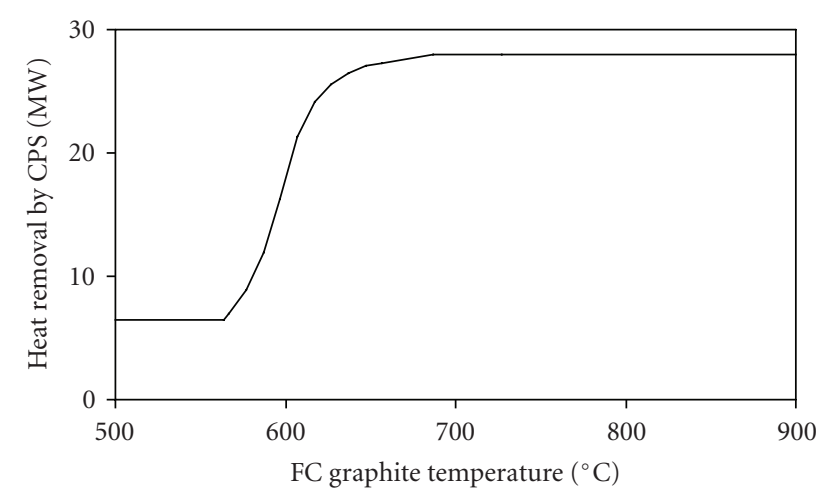

FIGURE 17: Dependency of removed heat capacity on the temperature of FCs graphite column, when regular CPS cooling circuit is available.

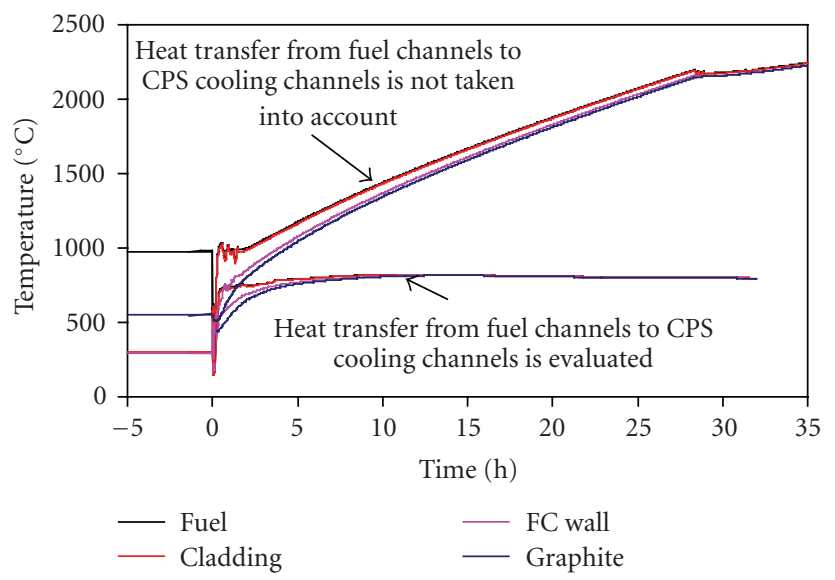

FIGURE 18: MCP pressure header break with failure of ECCS pumps. Behaviour of core components temperatures.

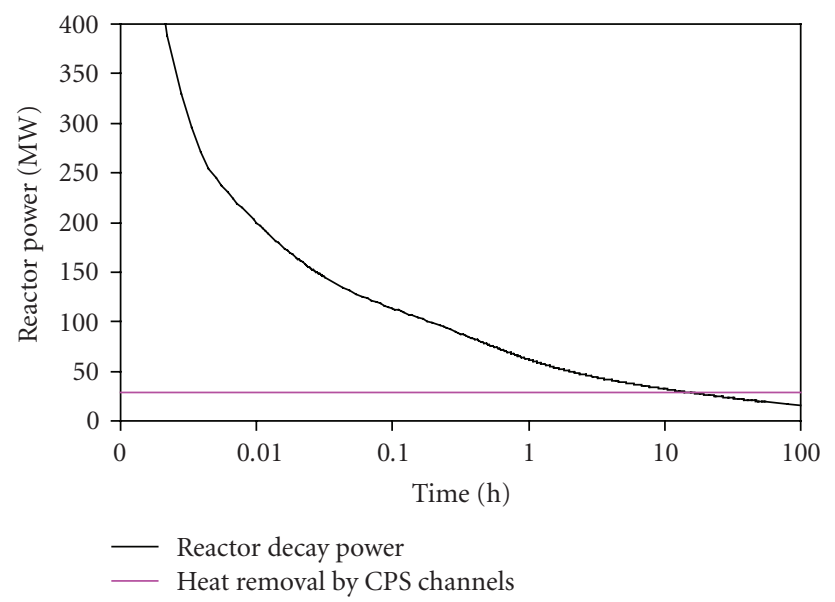

FIgURE 19: Comparison of reactor decay heat with capacity of heat removal from core by CPS cooling circuit (when regular CPS cooling system is available).

RELAP5 codes. The part of heat that can be removed by CPS in long-term accident becomes significant, when level of decay heat is decreased. In spite of high thermal inertia of 
graphite, this heat removal from CPS channels allows to slow down effectively the core heat-up process.

If regular CPS cooling circuit with the pumps and heat exchangers are available, this circuit can remove up to 28.5 MW from reactor core. Decay heat, generated in the core, decreases down to this level of heat, which is removed from CPS channels, 16 hours after the beginning of the accident. Starting from this time moment, the slow decrease of core components temperature begins. RELAP5 analysis shows that due to removal of heat from CPS channels, the peak fuel temperatures are below $1000^{\circ} \mathrm{C}$. Thus, in this case the use of this system allows to prevent zirconium oxidation and melting of stainless steel grids and fuel.

If the regular CPS cooling circuit is not available, there is a possibility to supply artesian water into CPS channels from AHS tank. The results of the analysis, performed using RELAP5-3D code, show that in this case only $15 \mathrm{MW}$ of heat can be removed from the core. This amount of removed heat is not enough to prevent serious consequences, but it allows to slow down the core heat-up process and may be used in complex with other measures.

\section{NOMENCLATURE}

\author{
$a, b, c:$ Coefficients \\ $\alpha: \quad$ Heat transfer coefficient of the gas gap, \\ $\mathrm{W} / \mathrm{m}^{2} \cdot \mathrm{K}$ \\ $\delta: \quad$ Gap dimension, $\mathrm{m}$ \\ $\varepsilon_{k}: \quad$ Convection coefficient \\ $n$ : Exponent \\ $\lambda_{\text {gas }}$ : Gas thermal conductivity coefficient, \\ $\mathrm{W} / \mathrm{m} \cdot \mathrm{K}$ \\ $\lambda_{e}: \quad$ Equivalent thermal conductivity coefficient, \\ $\mathrm{W} / \mathrm{m} \cdot \mathrm{K}$ \\ $T_{\mathrm{av}}$ : Average gas temperature, $\mathrm{K}$ \\ $\mathrm{Gr}_{\delta}$ : Grashof number \\ AA: Additional absorber \\ AHS: Additional hold-down system \\ CPS: Control and protection system \\ BDBA: Beyond design basis accidents \\ DS: Drum separator \\ ECCS: Emergency core cooling system \\ FA: Fuel assembly \\ FC: Fuel channel \\ GDH: Group distribution header \\ LOCA: Loss of coolant accident \\ MCP: Main circulation pump \\ MSV: Main safety valve \\ RCS: Reactor cooling system \\ RBMK: Russian acronym for "water-graphite boiling \\ reactor."
}

\section{REFERENCES}

[1] K. Almenas, A. Kaliatka, and E. Ušpuras, Ignalina RBMK-1500. A Source Book, Extended and Updated Version, Lithuanian Energy Institute, Kaunas, Lithuania, 1998.

[2] A. Kaliatka and E. Ušpuras, Accident and Transient Processes at NPPs with Channel-Type Reactors: Monography, vol. 28 of
Thermophysics, Lithuanian Energy Institute, Kaunas, Lithuanian, 2006.

[3] RELAP5-3D Code Manual, "Appendix A, RELAP5-3D Input Data Requirements," INEEL-EXT-98-00834-V2, 1998.

[4] S. Paik, "RELAP5-3D multidimensional heat conduction enclosure model for RBMK reactor application," Nuclear Technology, vol. 128, no. 1, pp. 87-102, 1999.

[5] E. Ušpuras and A. Kaliatka, "Evaluation of weak heat conduction mechanism model for long-term LOCAs in RBMK-1500," Nuclear Technology, vol. 158, no. 1, pp. 18-25, 2007.

[6] Ignalina NPP ICS database (Ignalina NPP second reactor unit condition on 16.04.1998).

[7] E. Ušpuras, E. Urbonavicius, and A. Kaliatka, "Specific features of the RBMK-1500 reactor and BDBA management," Energetika, vol. 2, no. 3, pp. 1-9, 2005.

[8] E. Ušpuras, A. Kaliatka, J. Augutis, S. Rimkevičius, E. Urbonavičius, and V. Kopustinskas, "Safety analysis of beyond design basis accidents in RBMK-1500 reactors," Annals of Nuclear Energy, vol. 34, no. 5, pp. 356-373, 2007.

[9] O. Yu. Novoselsky and V. N. Filinov, "Computational assessment of RBMK pressure tube rupture at accident heating," in International Exchange Forum on Analytical Methods and Computational Tools for NPP Safety Assessment, Obninsk, Russia, October 1996. 

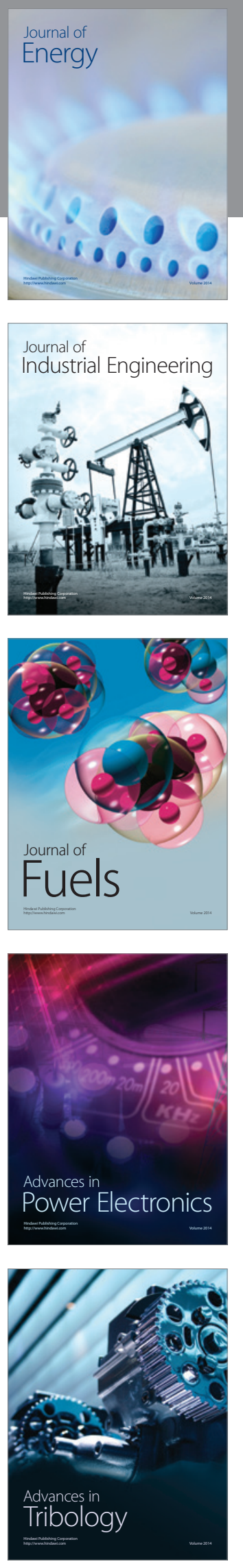
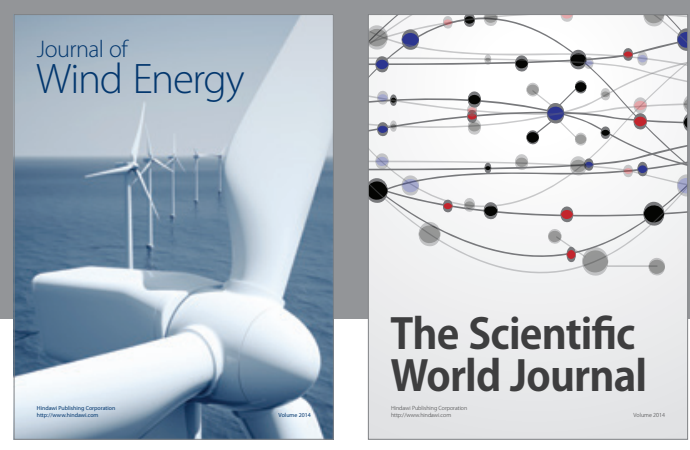

The Scientific World Journal

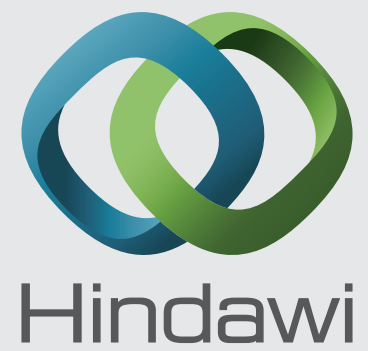

Submit your manuscripts at http://www.hindawi.com
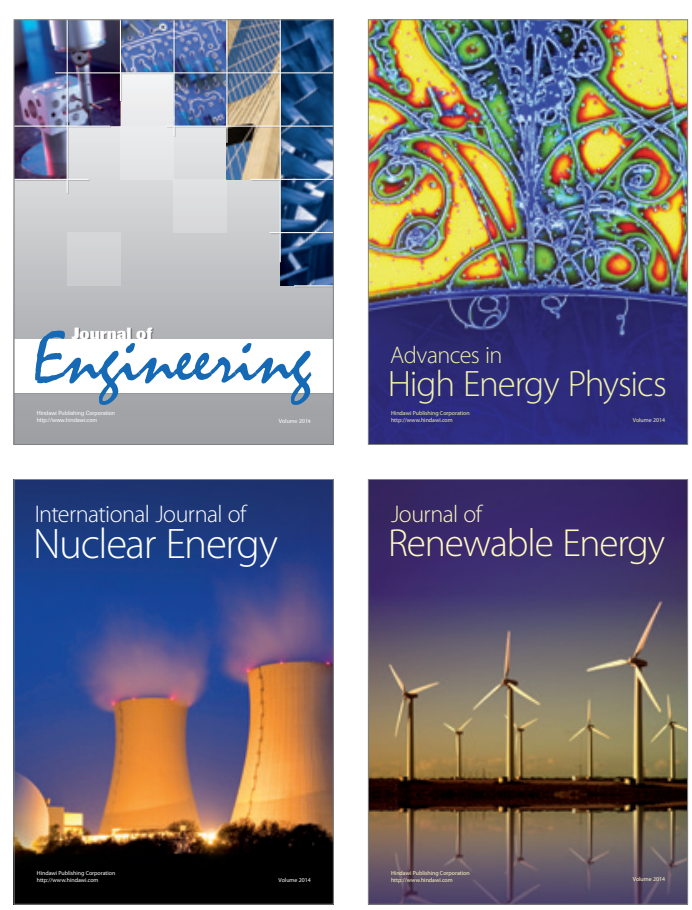

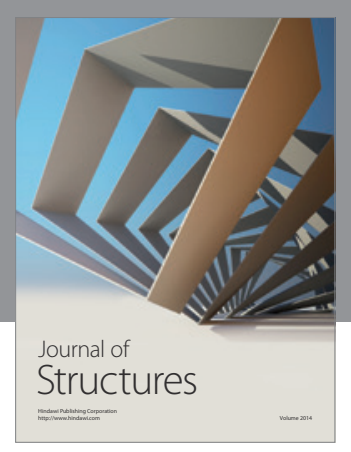

Rotating
Mechinery
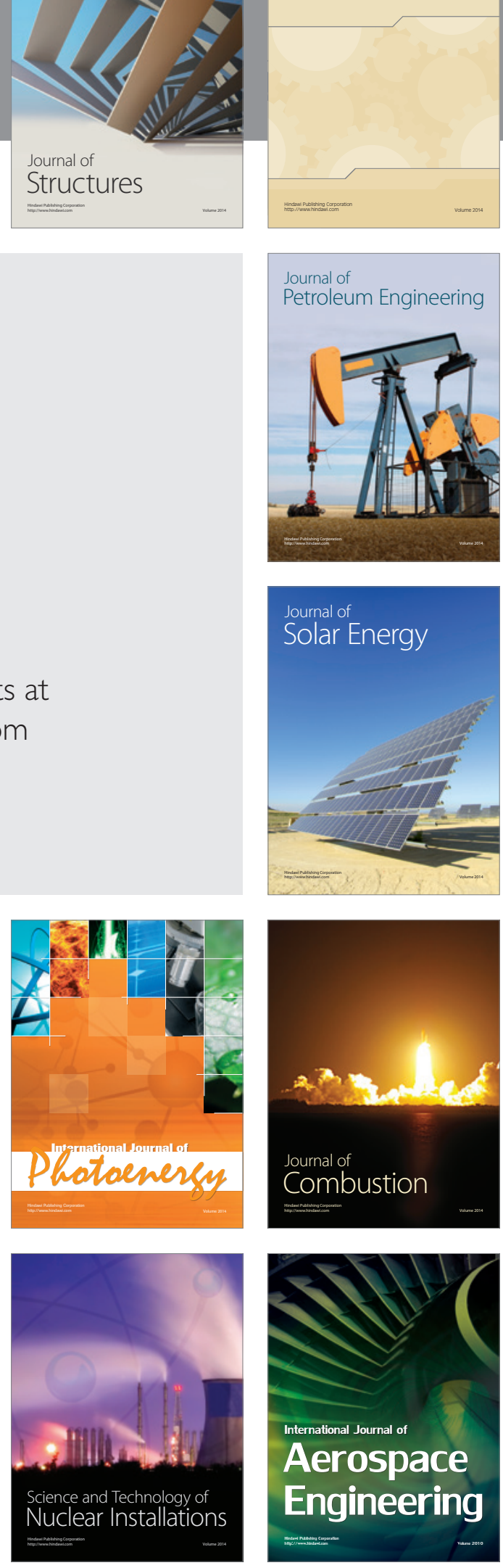